\title{
Expression of PD-L1 Identifies a Subgroup of More Aggressive Non-Small Cell Carcinomas of the Lung
}

\author{
William Sterlacci $^{a} \quad$ Michael Fiegl $^{b}$ Raoul A. Droeser ${ }^{c} \quad$ Alexandar Tzankov $^{d}$ \\ a Institute of Pathology, Klinikum Bayreuth, Bayreuth, Germany; ${ }^{b}$ Division of Hematology and Oncology, \\ Department of Internal Medicine, Medical University of Innsbruck, Innsbruck, Austria; ' Department of Surgery and \\ dInstitute of Pathology, University Hospital Basel, Basel, Switzerland
}

\section{Key Words}

Non-small cell lung cancer · PD-L1 · Prognosis

\begin{abstract}
Objectives: In light of various trials showing impressive response rates when treating non-small cell lung cancer (NSCLC) patients with anti PD-1/PD-L1 antibodies, the currently equivocal role of PD-L1 expression in NSCLC is in need of further clarification. Methods: We therefore analyzed the expression of PD-L1 on 293 well-documented NSCLC cases and correlated the results with clinical, histopathological and immunohistochemical characteristics. Results: The expression of PD-L1 on NSCLC was a poor prognostic factor for patients with nodal-negative adenocarcinoma (ACA) and, independent of other covariates, in tumors with increased CD8+ tumor-infiltrating lymphocytes (TILs). Expression of PD-L1 was more commonly seen in ACA and in male patients with a past and current smoking history. Finally, PD-L1+ TILs were more often found in squamous and large cell carcinomas. Conclusions: Should the expression of PD-L1 be on the verge of becoming an additional biomarker for routine diagnostics in NSCLC, our findings will provide important further insight and could contribute towards more effectively stratifying patients. These results may single out certain patient
\end{abstract}

groups with a potential for increased benefit from anti PD-1/ PD-L1 treatment strategies and should be considered in future trials.

(c) 2016 S. Karger AG, Basel

\section{Introduction}

The human immune system plays an important role in eliminating abnormal cells, which also applies to tumor cells and involves various effector cells, including $\mathrm{T}$ lymphocytes, natural killer (NK) cells and macrophages. Tumors, on the other hand, have several mechanisms that enable them to evade recognition and elimination. Among these are diminished antigen presentation, secretion of immunosuppressive substances, recruitment of inhibitory cells of the immune system and the herein emphasized interaction with immune checkpoints leading to T lymphocyte inactivation or even anergy [1-5]. For the full activation of a $\mathrm{T}$ cell, at least two signals are required: $\mathrm{T}$ cell receptor recognition of its ligand together with a major histocompatibility complex, as well as a costimulus

\section{R.A. Droeser and A. Tzankov share senior authorship.}

\section{KARGER}

E-Mail karger@karger.com www.karger.com/pat
(C) 2016 S. Karger AG, Basel

1015-2008/16/0835-0267\$39.50/0
W. Sterlacci, MD

Institute of Pathology, Klinikum Bayreuth

Preuschwitzerstrasse 101

DE-95445 Bayreuth (Germany)

E-Mail william.sterlacci@klinikum-bayreuth.de 
from an antigen-presenting cell [6]. This second signal is transmitted via B7-1 and/or B7-2 molecules on the antigen-presenting cell to the CD28 molecule on the respective T cell [6]. Various checkpoints exist to modulate immune responses in order to prevent the destruction of normal cells. Unfortunately, tumor cells are also able to interact with these checkpoints, thus evading antitumor immune reactions. Therefore, the targeting of these checkpoints is currently being pursued for treating cancer patients, often with remarkable results [7].

One of the most important checkpoints, especially within the tumor microenvironment, is the programmed death protein-1 (PD-1), a surface receptor and member of the B7-CD28 superfamily. PD-1 is expressed on activated T cells and interacts with its ligands PD-L1 (B7-H1) and PD-L2 (B7-DC), leading to the reduced proliferation, exhaustion and apoptosis of T cells $[8,9]$. PD-1 is also expressed on a subset of thymic T cells, NK cells, B cells, monocytes and dendritic cells $[8,10-12]$. The main ligand of PD-1 is PD-L1, which is an important member of the B7/CD28 costimulatory factor superfamily and is expressed on $\mathrm{T}$ cells, dendritic cells and macrophages in order to regulate an adequate immune response $[13,14]$. However, many epithelial cancers also express PD-L1 on their cell surface, resulting in T-cell anergy and escape from recognition and subsequent elimination by the immune system. PD-L1 expression by cancer cells has been discussed as a possible biomarker pointing towards a group of patients that might show an increased response to anti-PD-1/PD-L1 treatment [15]. The difficulties in utilizing $\mathrm{PD}-\mathrm{L} 1$ expression include the fact that it is dynamic and may be up- or downregulated, that several diagnostic antibodies exist, showing notable differences in specificity, and that there is no clearly defined cut-off value [16]. Although discrepancies regarding the prognostic value of PD-L1 expression in cancer have been reported, recent meta-analyses have shown that high PD-L1 expression is generally a marker of poor prognosis in nonsmall cell lung cancer (NSCLC) [17, 18]. It has also been shown that PD-L1 expression by NSCLC tumor cells is significantly associated with poor differentiation, an advanced $\mathrm{T}$ stage and consequently worse 5 -year survival $[19,20]$. However, others have reported that PD-L1 expression was devoid of any significant correlation with clinicopathological features or survival [21].

In light of various trials showing impressive response rates when treating NSCLC patients with anti PD-1/PD$\mathrm{L} 1$ antibodies, the currently equivocal role of PD-L1 expression calls for further clarification [22]. We therefore analyzed the expression of PD-L1 on a large cohort of well-documented NSCLC cases and correlated the results with abundant clinical, histopathological and immunohistochemical characteristics. Should the expression of PD-L1 be on the verge of becoming an additional biomarker for routine diagnostics in NSCLC, our findings will provide important further insight and could contribute towards more effectively stratifying patients.

\section{Materials and Methods}

\section{Patients and Tissue Sampling}

The archival samples were derived from NSCLC patients with radical surgical resection with curative intent between 1992 and 2004, who were diagnosed at the Institute of Pathology, Medical University of Innsbruck [23, 24]. Since only patients evaluable for PD-L1 expression are reported here, the cohort consists of 293 cases. Carcinoids were excluded from this analysis. Cases were selected only based on tissue preservation. Hematoxylin and eosinstained slides from all available specimens were reclassified by two pathologists (W.S. and A.T.) without knowledge of the patient data, according to the current (2015) WHO classification of tumors of the lung [25]. Tumor differentiation was graded as either well, moderate or poor. The clinical information was documented within the TYROL (Twenty Years Retrospective of Lung Cancer) survey, a project aiming to analyze various features of a large number of lung cancer patients [26]. Approval for data acquisition and analysis was obtained from the Ethics Committee of the Medical University of Innsbruck.

\section{Tissue Microarray Construction}

Tumor material consisted of paraffin-embedded tissue after fixation in $10 \%$ neutral-buffered formalin. The tissue microarray was constructed as previously described [23]. The first sections were stained by hematoxylin and eosin to confirm their validity, and the following were used for immunohistochemistry.

\section{Immunohistochemistry}

In order to assess the optimal staining for PD-L1, two different antibodies [clone E1L3N (Cell Signaling, Danvers, Mass., USA) and clone SP142 (Roche/Ventana, Rotkreuz, Switzerland)] were evaluated on classical Hodgkin lymphoma cases with known $9 p 21$ (PDL1 locus) gains and NSCLC tissue, as well as reactive lymph node and tonsillar tissue (fig. 1a-c) [27, 28]. The staining pattern of both antibodies was as expected: membranous/submembranous with occasional dots, corresponding to the PD-1PD-L1 interaction sites (talk given by Dr. Banks from Roche/ Ventana at the 2015 SH Workshop on Immunodeficiency and Dysregulation, Long Beach, Calif., USA). In reactive lymph nodes the sinus-lining cells (fig. 1c) as well as macrophages stained positively, as expected. Finally, the E1L3N antibody clone was chosen to be used for further evaluations primarily because of the better signal-to-noise results and considerably lower price; in addition, this antibody has already been used by other groups showing reliable staining results [29]. The slides were processed on an automated immunostainer (Benchmark, Ventana/Roche, Tucson, Ariz., USA). The dilution of the primary E1L3N antibody 
Fig. 1. Comparison of two commercially available PD-L1 antibodies and validation of the E1L3N clone. a Poorly differentiated ACA of the lung spreading along a bronchus with squamous metaplasia stained with the SP142 clone. Original magnification $\times 20$. b The same case stained with the E1L3N clone; identical magnification. Note the better signal-to-noise ratio as well as higher amount of positively staining macrophages and the weak staining of the basal squamous epithelial cells. c Positively staining Reed-Sternberg cells of classical Hodgkin lymphoma with known PDL1 locus amplification. Original magnification $\times 400$. d Positively staining sinus-lining cells and macrophages in a reactive lymph node. Original magnification $\times 360$.

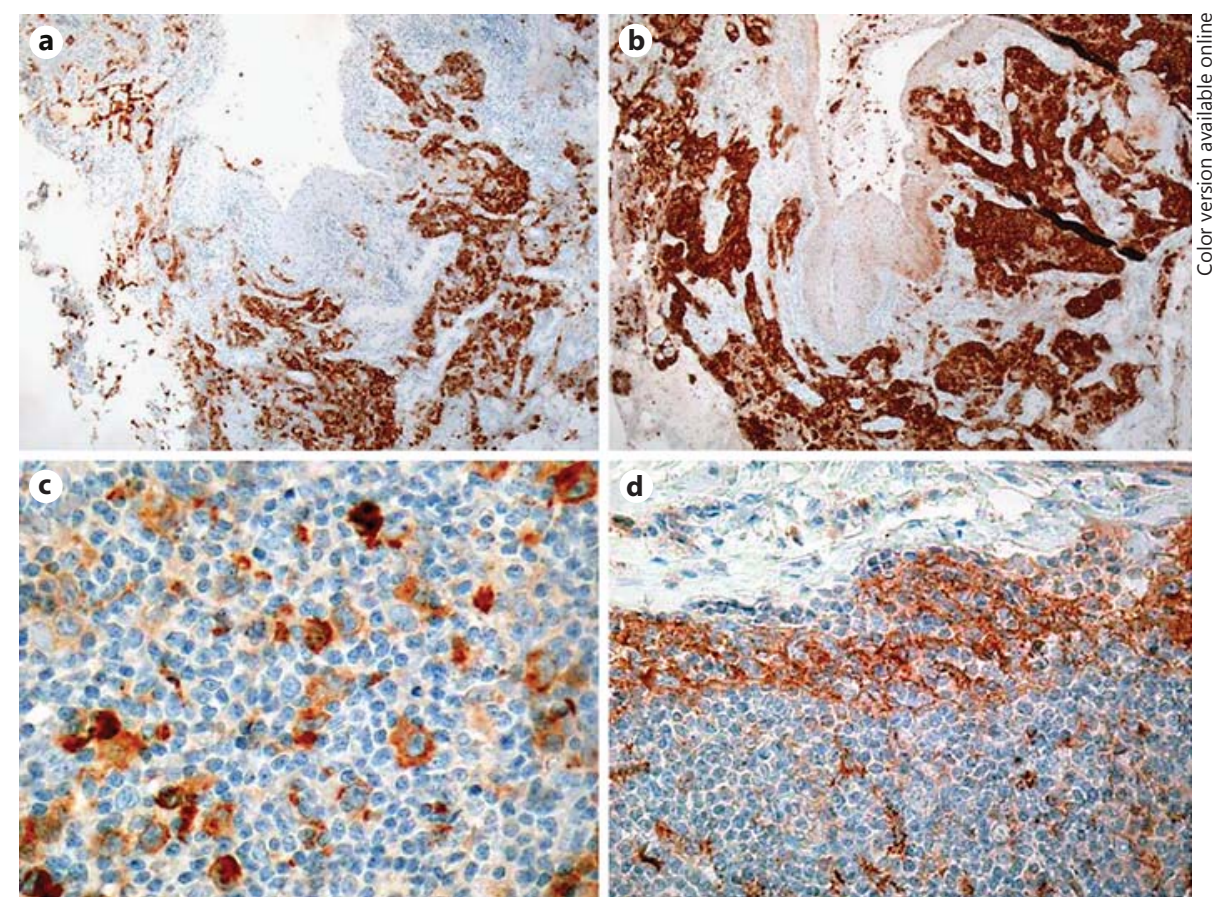

was 1:50. Antigen retrieval was performed applying Cell Conditioning 1 (Ventana/Roche 950-124) for $24 \mathrm{~min}$. 3,3'-diaminobenzidine was used as chromogen and the slides were then counterstained with hematoxylin.

\section{Immunohistochemical Evaluation}

Only cores containing at least twenty vital tumor cells were evaluated. If all four spots of a case did not meet this criterion it was excluded, thus the minimum tumor cell count of evaluated cases was eighty ( 4 cores with $\geq 20$ tumor cells). The percentage of positively stained cells with clearly visible membranocytoplasmic staining was noted for each spot, followed by the calculation of the arithmetic mean value. Finally, cases were grouped depending on the number of positively staining tumor cells into those expressing PD-L1 in $1-4,5-49,50-74$ and $>74 \%$. The presence of PD-L1positive tumor-infiltrating lymphocytes (TILs) and macrophages (TIMs) was recorded as positive or negative, depending on whether they were observable or not. The prognostic relevance of PD-L1 was assessed for each category and a cut-off score of $>5 \%$, which is also most commonly suggested in the literature, appeared to be most relevant and was later used for dichotomization [30, 31].

\section{Statistical Analysis}

A correlation analysis of clinicopathological and immunohistochemical parameters was performed using the Spearman test in cases where histological subtypes were separately analyzed, corrected for multiple testing (considering $\mathrm{p}$ values $\leq 0.01$ ); only correlations with $\rho$ of at least \pm 0.15 were reported. In addition, for the histology types, the distributions of PD-L1-expressing tumors according to the above-mentioned categories were compared by means of the $\chi^{2}$ test. Kaplan-Meier curves were calculated for survival estimates and the log-rank statistics used to determine differences between groups; multivariable analysis was performed using the Cox regression model; when not corrected for multiple testing, $p$ values $<0.05$ were considered significant. Two-sided tests were used throughout. Statistical calculations were performed using SPSS 22.0 software (SPSS, Chicago, Ill., USA).

\section{Results}

\section{Histopathology and Patient Characteristics}

Histological subtypes consisted of 170 adenocarcinomas (ACA), 95 squamous cell carcinomas (SCC), 19 large cell carcinomas (LCC; including 8 neuroendocrine LCC cases), 7 adenosquamous carcinomas, 1 sarcomatoid carcinoma of the pleomorphic type and 1 mucoepidermoid carcinoma. The patient characteristics are presented in detail in table 1.

\section{Immunohistochemistry}

Quantitative and qualitative immunohistochemical data are shown in table 2 and figure $2 \mathrm{a}-\mathrm{f}$. In cases of ACA, PD-L1 positivity in $\geq 5 \%$ of the tumor cells was exclusively observed in solid and acinar subtypes. The staining pattern observed was membranous and membranocytoplasmic.

\section{Correlations between Variables}

In addition to the presently studied markers, previously assessed molecular parameters were incorporated here 
Table 1. Patient characteristics

\begin{tabular}{|c|c|c|c|}
\hline Variables & $\begin{array}{l}\text { All histological } \\
\text { subtypes } \\
(n=293)\end{array}$ & $\begin{array}{l}\text { ACA } \\
(n=170)\end{array}$ & $\begin{array}{l}\text { SCC } \\
(n=95)\end{array}$ \\
\hline \multicolumn{4}{|l|}{ Sex } \\
\hline Female & 81 & 63 & 14 \\
\hline Male & 212 & 107 & 81 \\
\hline \multicolumn{4}{|l|}{ Age } \\
\hline$\leq 65$ years & 165 & 100 & 50 \\
\hline$>65$ years & 128 & 70 & 45 \\
\hline \multicolumn{4}{|l|}{ pUICC stage } \\
\hline IA & 78 & 49 & 21 \\
\hline IB & 87 & 41 & 34 \\
\hline IIA & 15 & 11 & 4 \\
\hline IIB & 35 & 16 & 17 \\
\hline IIIA & 44 & 29 & 13 \\
\hline IIIB & 13 & 9 & 2 \\
\hline IV & 16 & 13 & 2 \\
\hline \multicolumn{4}{|l|}{ T stage } \\
\hline $1^{\circ}$ & 189 & 73 & 25 \\
\hline 2 & 146 & 72 & 58 \\
\hline 3 & 22 & 13 & 8 \\
\hline 4 & 14 & 10 & 2 \\
\hline Unknown & 5 & 2 & 2 \\
\hline \multicolumn{4}{|l|}{$\mathrm{N}$ stage } \\
\hline 0 & 189 & 105 & 60 \\
\hline 1 & 61 & 36 & 23 \\
\hline 2 & 38 & 27 & 10 \\
\hline Unknown & 5 & 2 & 2 \\
\hline \multicolumn{4}{|l|}{ M stage } \\
\hline 0 & 272 & 155 & 91 \\
\hline 1 & 16 & 13 & 2 \\
\hline Unknown & 5 & 2 & 2 \\
\hline \multicolumn{4}{|l|}{ Tumor grade } \\
\hline Well & 18 & 16 & 1 \\
\hline Moderate & 123 & 82 & 37 \\
\hline Poor & 152 & 72 & 57 \\
\hline \multicolumn{4}{|l|}{ Recurrences } \\
\hline No & 151 & 79 & 54 \\
\hline Yes & 142 & 91 & 41 \\
\hline \multicolumn{4}{|l|}{ Smoker } \\
\hline Never & 13 & 11 & 2 \\
\hline Ever & 174 & 84 & 67 \\
\hline Unknown & 106 & 75 & 26 \\
\hline
\end{tabular}

as well $[23,24,32-36]$. For the whole cohort, expression of PD-L1 in $\geq 5 \%$ of the tumor cells correlated with the expression of CD95 ( $\rho=0.254, p=0.00001)$, osteopontin $(\rho=0.183, p=0.002)$, active caspase $3(\rho=0.161, p=$ $0.006)$, increased amounts of PD- $1+$ TILs $(\rho=0.185, \mathrm{p}=$ $0.002)$, increased amounts of CD8+ TILs $(\rho=0.174, p=$ 0.003 ), and higher proliferative tumor activity as assessed by the expression of KI67 ( $\rho=0.191, p=0.001)$.
Table 2. Immunohistochemical PD-L1 expression profiles

\begin{tabular}{lcrlll}
\hline Histotype & $1-4 \%$ & $5-49 \%$ & $50-74 \%$ & $75-100 \%$ & $\begin{array}{l}\text { TILs and } \\
\text { TIMs }\end{array}$ \\
\hline ACA $(\mathrm{n}=170)$ & $17(10)$ & $16(9)$ & $6(4)$ & $4(2)$ & $20(12)$ \\
SCC $(\mathrm{n}=95)$ & $2(2)$ & $4(4)$ & $3(3)$ & $1(1)$ & $16(17)$ \\
LCC $(\mathrm{n}=19)$ & $2(10)$ & $0(0)$ & $0(0)$ & $0(0)$ & $5(26)$ \\
ASC $(\mathrm{n}=7)$ & $3(43)$ & $0(0)$ & $0(0)$ & $0(0)$ & $0(0)$ \\
MEC $(\mathrm{n}=1)$ & $0(0)$ & $0(0)$ & $0(0)$ & $0(0)$ & $0(0)$ \\
SRC $(\mathrm{n}=1)$ & $0(0)$ & $0(0)$ & $1(100)$ & $0(0)$ & $0(0)$ \\
\hline p value & 0.00024 & & & 0.019 \\
\hline
\end{tabular}

Values in parentheses are percentages. ASC $=$ Adenosquamous carcinoma; $\mathrm{MEC}=$ mucoepidermoid carcinoma; $\mathrm{SRC}=$ sarcomatoid carcinoma.

With respect to PD-L1+ TILs and TIMs in the whole cohort, their presence correlated inversely with pCXCR4 in the tumor stroma $(\rho=-0.212, p=0.001)$. Interestingly enough, although not significant because of the limited number of nonsmokers, PD-L1+ TILs and TIMs were observable only in ever-smoking patients.

In cases of ACA, the expression of PD-L1 in $\geq 5 \%$ of the tumor cells correlated with CD95 $(\rho=0.309, \mathrm{p}=$ $0.00001)$, osteopontin $(\rho=0.237, p=0.002)$, active caspase $3(\rho=0.229, p=0.003)$, the expression of CD44 $(\rho=0.219, \mathrm{p}=0.005)$, the expression and phosphorylation (activation) of CXCR4 ( $\rho=0.217, p=0.008$ for CXCR4, and $\rho=0.186, p=0.023$ for $\mathrm{pCXCR} 4$ ), increased amounts of PD- $1+$ TILs $(\rho=0.206, p=0.009)$, increased amounts of FOXP3+ TILs $(\rho=0.218, p=0.005)$ and higher proliferative tumor activity $(\rho=0.307, p=0.001)$. Although not significant (corrected for multiple testing), the expression of PD-L1 in $\geq 5 \%$ of the tumor cells in ACA correlated with EGFR amplifications $(\rho=0.230, p=0.031)$ and deletions of CDKN2A ( $p 16)(\rho=0.167, p=0.046)$. With respect to PD-L1+ TILs and TIMs in ACA, there was an inverse correlation with pCXCR4 in the tumor stroma $(\rho=-0.266, p=0.001)$ and higher proliferative tumor activity of the tumor $(\rho=-0.215, p=0.005)$ and, conversely, with D2-40 positivity of the tumor stroma $(\rho=0.219, p=0.005)$.

In cases of SCC, expression of PD-L1 in $\geq 5 \%$ of the tumor cells correlated with active caspase 3 ( $\rho=0.249$, $\mathrm{p}=0.01)$, marginally with increased amounts of CD8+ TILs $(\rho=0.226, p=0.032)$ and with male gender $(\rho=$ $0.209, \mathrm{p}=0.043$ ). With respect to PD-L1+ TILs and TIMs in SCC, there was a correlation with caspase 3 activity in the tumor $(\rho=0.322, p=0.001)$, and a marginal correla- 

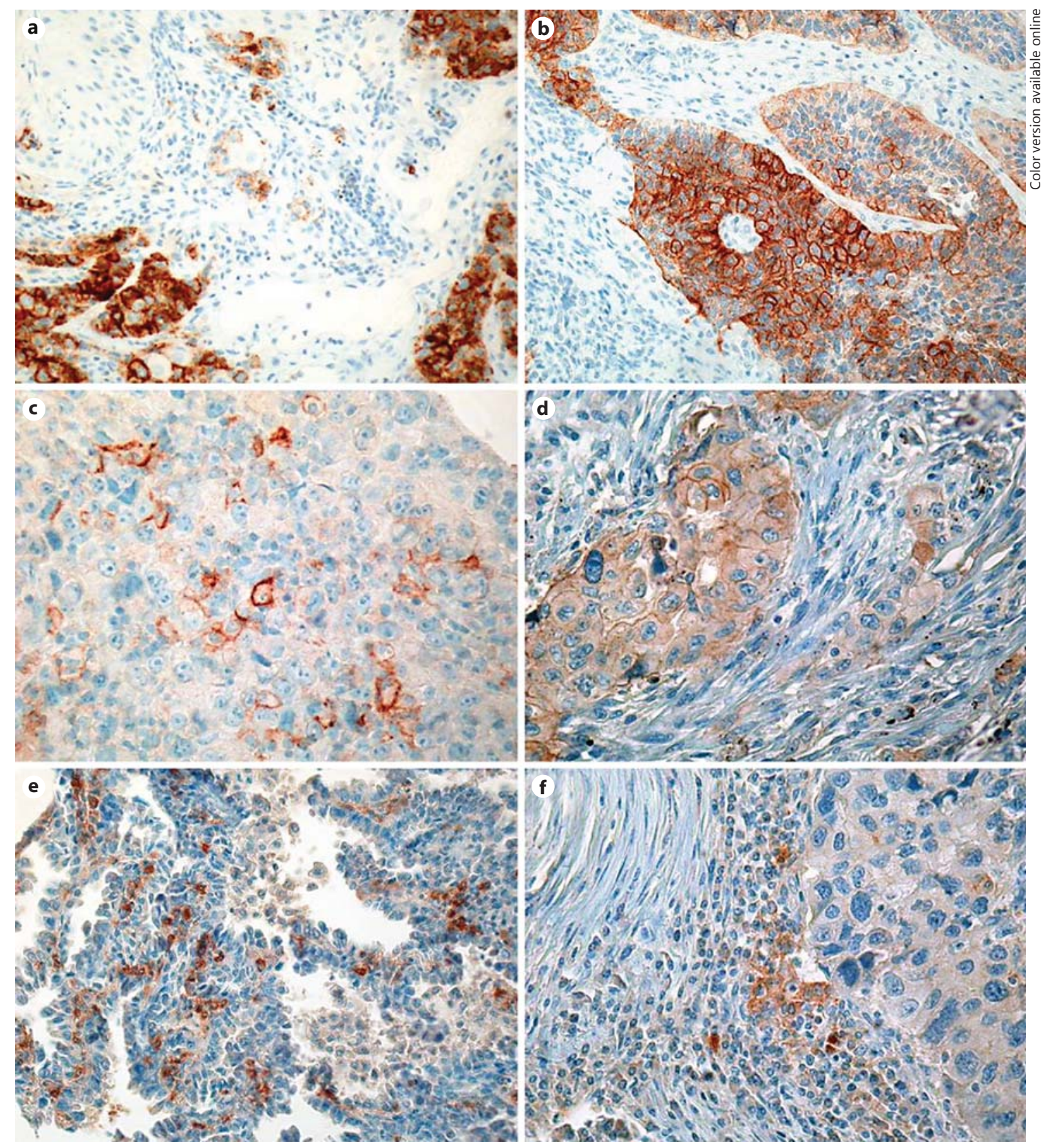

Fig. 2. PD-L1 expression. a Highly positive ACA. Original magnification $\times 100$. b Highly positive SCC. Original magnification $\times 120$. c ACA expressing PD-L1 in $5-10 \%$ of tumor cells. Original magnification $\times 360$. d SCC expressing PD-L1 in $5-10 \%$ of tumor cells. Original magnification $\times 240$. e ACA with PD-L1+ TILs and TIMs. Original magnification $\times 160$. f SCC with PD-L1+ TILs and TIMs. Original magnification $\times 240$.

tion with the amount of TGF $\beta+$ TILs $(\rho=0.235, \mathrm{p}=$ $0.032)$ and frequencies of relapses $(\rho=0.233, p=0.023)$, i.e. there were 11 relapses observable in the 16 SCC cases with PD-L1+ TILs and TIMs (69\%), compared to 30 relapses in the 79 SCC cases without PD-L1+ TILs and TIMs (38\%).

PD-L1 Expression in Non-Small Cell Lung Cancer

\section{Survival Analysis}

Exploratory (i.e. not corrected for multiple testing) analyses on the prognostic significance of overall and relapse-free survival in the three major histological subtypes (ACA, SCC and LCC), unstratified and stratified for $\mathrm{pN}$ stage, revealed an impact on the outcome of PD-L1+

Pathobiology 2016;83:267-275 


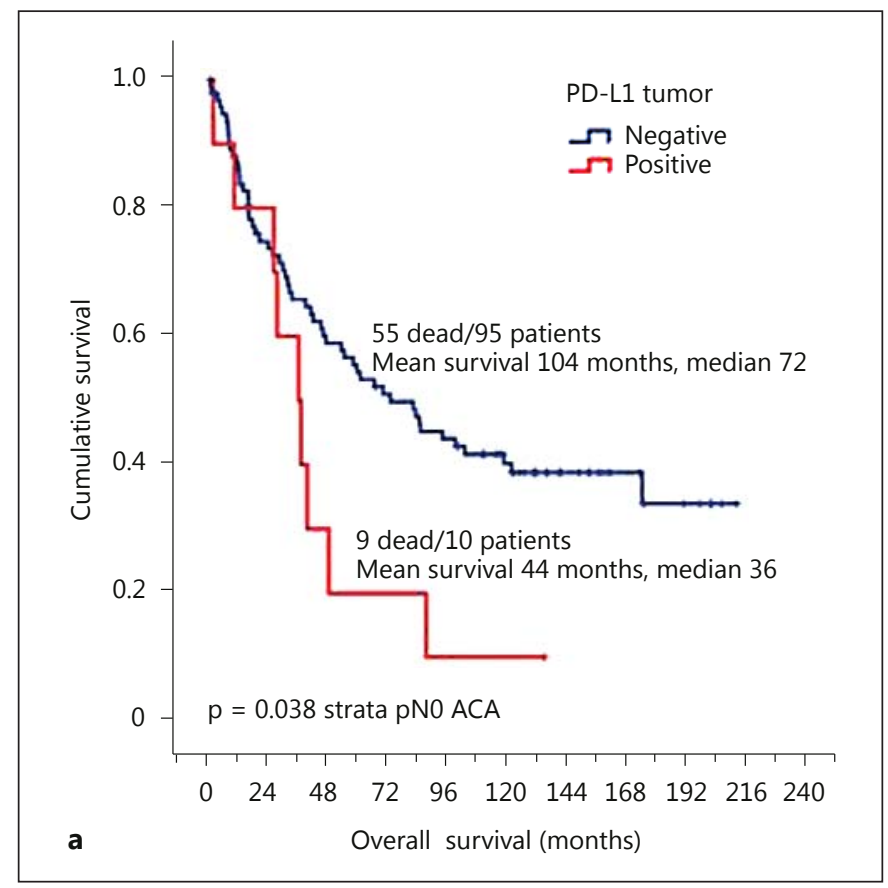

Fig. 3. Survival analysis respecting PD-L1 expression and the presence of PD-L1+ TILs and TIMs. a Worse overall survival of patients with $\mathrm{PD}-\mathrm{L} 1+$ nodal-negative (pN0) ACA. b Worse relapsefree survival of patients with SCC with increased amounts of PDL1+ TILs and TIMs. c Overall survival of the NSCLC patient subgroup with increased amounts of CD8+ TILs respecting PD-L1 expression by the tumor.

expression in $\geq 5 \%$ of the tumor cells in pN0 ACA ( $\mathrm{p}=$ 0.038 ) (fig. 3a) and a potential impact on relapse-free survival of PD-L1+ TILs and TIMs in SCC $(\mathrm{p}=0.076)$ (fig. 3b). When NSCLC cases were stratified according to the presence or absence of CD8+ TILs, defined as $>10 \%$ CD8+ TILs [33], expression of PD-L1 in $\geq 5 \%$ of the tu-
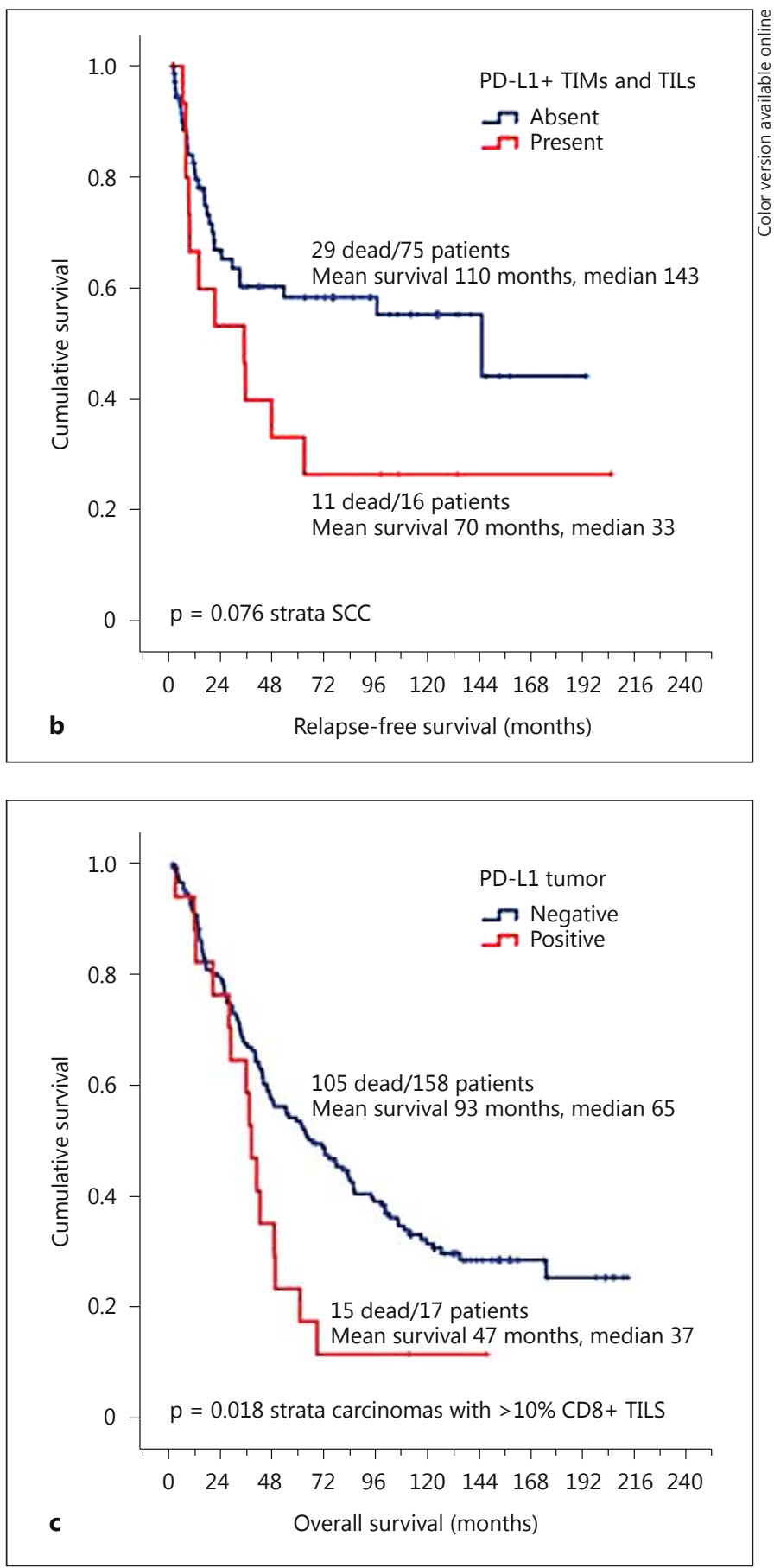

mor cells had a significant impact on survival $(\mathrm{p}=0.018)$ (fig. 3c).

When all significant parameters (including previous publications [23, 24, 33-36]) by univariate analysis (higher pT stage, higher age, expression loss of p16, higher KI67 and P-glycoprotein expression) were tested by mul- 
Table 3. Multivariable analysis of the prognostic role of PD-L1 expression in tumor cells of pN0 ACA

\begin{tabular}{llll}
\hline (Bio)marker & $\begin{array}{l}\text { p } \\
\text { value }\end{array}$ & RR & $\begin{array}{l}\text { 95\% CI for } \\
\text { RR }\end{array}$ \\
\hline p16 loss $(<10 \%)$ & 0.001 & 2.564 & $1.464-4.484$ \\
pT stage (higher) & 0.052 & 1.438 & $0.997-2.074$ \\
PD-L1 expression $(>5 \%)$ & 0.322 & 1.114 & $0.900-1.379$ \\
P-glycoprotein expression $(>4.5 \%)$ & 0.349 & 1.289 & $0.758-2.192$ \\
Proliferative activity (KI67 $>3 \%)$ & 0.901 & 1.036 & $0.592-1.814$ \\
Age $>63$ years (median) & 0.978 & 1.007 & $0.598-1.697$ \\
\hline
\end{tabular}

$\mathrm{RR}=$ Relative risk

tivariate analysis, the expression of PD-L1 in $\geq 5 \%$ of the tumor cells in pN0 ACA proved not to be an independent prognostic factor (table 3) [37]. However, PD-L1 expression in $\geq 5 \%$ of the tumor cells was of significance in the subgroup of NSCLC with increased CD8+ TILs when compared to the pUICC stage, age, gender and expression loss of p16 (table 4).

\section{Discussion}

PD-L1 expression was analyzed in a large cohort of thoroughly documented NSCLC cases using a validated antibody. Our findings show that the expression of PDL1 on NSCLC is a poor prognostic factor in nodal-negative ACA and, independent of other factors, in NSCLC with increased CD8+ TILs. Expression of PD-L1 is more commonly seen in ACA and male patients with a past and current smoking history. PD-L1+ TILs and TIMs are more often found in SCC and LCC and are of a possible adverse prognostic importance in SCC.

PD-L1 expression has been discussed as a potential biomarker for response to treatment with anti-PD-1/PDL1 strategies; however, PD-L1 immunohistochemistry is known to be technically difficult [38]. Furthermore, neither validated assays nor clearly defined cut-off values exist. We therefore validated and applied a properly working PD-L1 antibody. A cut-off of $>5 \%$ is often proposed due to its correlation with a clinical response to anti-PDL1 therapy [30, 31]. This indeed seems to be an appropriate cut-off value since it also proved to be prognostically relevant in our present study. PD-L1 expression has been reported in association with higher tumor grades in NSCLC, as well as with higher proliferation rates as assessed by KI67 in other cancers [17, 18, 39]. This is in line
Table 4. Multivariable analysis of the prognostic role of PD-L1 expression in tumor cells of NSCLCs with increased CD8+ tumorinfiltrating lymphocytes

\begin{tabular}{llll}
\hline (Bio)marker & $\begin{array}{l}\mathrm{p} \\
\text { value }\end{array}$ & $\mathrm{RR}$ & $\begin{array}{l}\text { 95\% CI for } \\
\mathrm{RR}\end{array}$ \\
\hline pUICC & 0.002 & 1.170 & $1.062-1.290$ \\
Gender (male) & 0.015 & 1.710 & $1.111-2.633$ \\
PD-L1 expression $(>5 \%)$ & 0.014 & 1.194 & $1.037-1.374$ \\
Age $>$ 63 years (median) & 0.048 & 1.469 & $1.004-2.150$ \\
p16 loss $(<10 \%)$ & 0.073 & 1.424 & $0.968-2.096$ \\
\hline
\end{tabular}

$\mathrm{RR}=$ Relative risk.

with our findings as PD-L1-positive NSCLC showed a higher KI67 rate, although - and therapeutically intriguing - it also exhibited markers indicating apoptosis readiness (CD95, active caspase 3 ) and higher amounts of (potentially anergized) CD8+ TILs. We found that PD-L1 expression is more frequent in male patients and that in ACA it is associated with CDKN2A deletions, altogether pointing towards a possible smoker signature. Underlining this hypothesis, the presence of PD-L1 on TILs and TIMs was also only detected in past and current smokers. This may be an explanation for why smokers show a better response to PD-L1 inhibitors [40].

PD-L1+ NSCLC seem to interact with the immune system and further promote their anti-tumor effect by attracting immunosuppressive PD-L1+ TILs and FOXP3+ TILs (in ACA) as well as TGF- $\beta+$ TILs (in SCC) as evidenced by the observed higher amounts of the respective TILs in our cohort. PD-L1 also weakly correlated with Casitas B-lineage lymphoma proto-oncogene B, a negative regulator of $\mathrm{T}$ cell activation (data not shown, $\rho=$ $0.133, \mathrm{p}=0.027$ ). Thus, PD-L1 expression in tumor cells is obviously at least locally immunosuppressive. On the other hand, these tumors also have increased numbers of CD8+ TILs, which might represent a compensatory attempt by the immune system. In the case of successfully inhibiting PD-L1, these CD8+ TILs could regain their desired effect of eliminating tumor cells. This may be especially important since we could demonstrate that tumors harboring increased CD8+ TILs are, independently of other factors, associated with poorer survival when expressing $\mathrm{PD}$-L1, despite showing a trend for a better prognosis (data not shown, $\mathrm{p}=0.066$ ) when PD-L1 is not taken into account. This suggests that PD-L1 has the potential to restrain CD8+ TIL activity, which is obviously prognostically important (patients with lower levels of 
CD8+ TILs showed no such effect). In line with the observed higher KI67 proliferation rate, PD-L1 appears to increase the aggressiveness in NSCLC, since patients with nodal-negative PD-L1+ ACA have a significantly worse prognosis than their PD-L1- counterparts. In addition, patients with PD-L1+ SCC more frequently suffer from disease recurrences compared to SCC patients without PD-L1 expression. Therefore, PD-L1 expression may identify good NSCLC candidates for (even adjuvant) therapeutic PD-L1 inhibition. PD-L1+ ACA showed a correlation with activated CXCR4. This is another sign for tumor aggressiveness, since CXCR4 is activated by SDF-1, and both have been reported as poor prognostic markers [41, 42]. Furthermore, since CXCR4 is responsible for lymphoid cell quiescence, this may be an additional means by which PD-L1+ tumor cells interact with the immune system to evade immune responses. Finally, we noticed a negative correlation between PD-L1+ TILs and TIMs with PCXCR4, and a positive correlation with
D2-40, with both present in the tumor stroma. Considering the above-mentioned effect of CXCR4 on lymphoid cells, the explanation might be that low levels of CXCR4 lead to the attraction of TILs and TIMs.

In summary, using a validated PD-L1 antibody and a large cohort of meticulously documented NSCLC cases, we could confirm the prognostic importance of PD-L1 expression for NSCLC patients, especially for patients with nodal-negative ACA and, independent of other factors, in NSCLC with increased amounts of CD8+ TILs. These results may single out certain patient groups with a potential for increased benefit from anti-PD-1/PD-L1 treatment strategies and should be considered in future trials.

\section{Disclosure Statement}

The authors have no conflicts of interest to declare.

\section{References}

1 Zitvogel L, Tesniere A, Kroemer G: Cancer despite immunosurveillance: immunoselection and immunosubversion. Nat Rev Immunol 2006;6:715-727.

2 Kerkar SP, Restifo NP: Cellular constituents of immune escape within the tumor microenvironment. Cancer Res 2012;72:3125-3130.

3 Pardoll DM: The blockade of immune checkpoints in cancer immunotherapy. Nat Rev Cancer 2012;12:252-264.

4 Platonova S, Cherfils-Vicini J, Damotte D, et al: Profound coordinated alterations of intratumoral NK cell phenotype and function in lung carcinoma. Cancer Res 2011;71:54125422.

5 Rabinovich GA, Gabrilovich D, Sotomayor EM: Immunosuppressive strategies that are mediated by tumor cells. Annu Rev Immunol 2007;25:267-296.

6 Lipson EJ, Drake CG: Ipilimumab: an antiCTLA-4 antibody for metastatic melanoma. Clin Cancer Res 2011;17:6958-6962.

7 Pentcheva-Hoang T, Corse E, Allison JP: Negative regulators of T-cell activation: potential targets for therapeutic intervention in cancer, autoimmune disease, and persistent infections. Immunol Rev 2009;229:67-87.

8 Jin HT, Ahmed R, Okazaki T: Role of PD-1 in regulating T-cell immunity. Curr Top Microbiol Immunol 2011;350:17-37.

9 Zielinski C, Knapp S, Mascaux C, et al: Rationale for targeting the immune system through checkpoint molecule blockade in the treatment of non-small-cell lung cancer. Ann Oncol 2013;24:1170-1179.
10 Shi L, Chen S, Yang L, et al: The role of PD-1 and PD-L1 in T-cell immune suppression in patients with hematological malignancies. J Hematol Oncol 2013;6:74.

11 Latchman Y, Wood CR, Chernova T, et al: PD-L2 is a second ligand for PD-1 and inhibits T cell activation. Nat Immunol 2001;2: 261-268.

12 Kitazawa Y, Fujino M, Wang Q, et al: Involvement of the programmed death-1/ programmed death-1 ligand pathway in CD4+CD25+ regulatory T-cell activity to suppress alloimmune responses. Transplantation 2007;83:774-782.

13 Xu F, Xu L, Wang Q, et al: Clinicopathological and prognostic value of programmed death ligand-1 (PD-L1) in renal cell carcinoma: a meta-analysis. Int J Clin Exp Med 2015;8: 14595-14603.

14 Afreen S, Dermime S: The immunoinhibitory B7-H1 molecule as a potential target in cancer: killing many birds with one stone. Hematol Oncol Stem Cell Ther 2014;7:1-17.

15 Langer CJ: Emerging immunotherapies in the treatment of non-small cell lung cancer (NSCLC): the role of immune checkpoint inhibitors. Am J Clin Oncol 2015;38:422-430.

16 Muenst S, Soysal SD, Tzankov A, et al: The PD-1/PD-L1 pathway: biological background and clinical relevance of an emerging treatment target in immunotherapy. Expert Opin Ther Targets 2015;19:201-211.
17 Pan ZK, Ye F, Wu X, et al: Clinicopathological and prognostic significance of programmed cell death ligand1 (PD-L1) expression in patients with non-small cell lung cancer: a metaanalysis. J Thorac Dis 2015;7:462-470.

18 Wang A, Wang HY, Liu Y, et al: The prognostic value of PD-L1 expression for non-small cell lung cancer patients: a meta-analysis. Eur J Surg Oncol 2015;41:450-456.

19 Chen YB, Mu CY, Huang JA: Clinical significance of programmed death-1 ligand-1 expression in patients with non-small cell lung cancer: a 5-year-follow-up study. Tumori 2012;98:751-755.

$20 \mathrm{Mu} \mathrm{CY}$, Huang JA, Chen Y, et al: High expression of PD-L1 in lung cancer may contribute to poor prognosis and tumor cells immune escape through suppressing tumor infiltrating dendritic cells maturation. Med Oncol 2011;28:682-688.

21 Konishi J, Yamazaki K, Azuma M, et al: B7$\mathrm{H} 1$ expression on non-small cell lung cancer cells and its relationship with tumor-infiltrating lymphocytes and their PD-1 expression. Clin Cancer Res 2004;10:5094-5100.

22 Bustamante Alvarez JG, González-Cao M, et al: Advances in immunotherapy for treatment of lung cancer. Cancer Biol Med 2015;12:209222

23 Sterlacci W, Fiegl M, Hilbe W, et al: Clinical relevance of neuroendocrine differentiation in non-small cell lung cancer assessed by immunohistochemistry: a retrospective study on 405 surgically resected cases. Virchows Arch 2009;455:125-132. 
24 Sterlacci W, Savic S, Fiegl M, et al: Putative stem cell markers in non-small-cell lung cancer: a clinicopathologic characterization. J Thorac Oncol 2014;9:41-49.

25 Travis W, Brambilla E, Burke A, et al: WHO Classification of Tumours of the Lung, Pleura, Thymus and Heart. Lyon, IARC Press, 2015.

26 Kocher F, Hilbe W, Seeber A, et al: Longitudinal analysis of 2293 NSCLC patients: a comprehensive study from the TYROL registry. Lung Cancer 2015;87:193-200.

27 Meier C, Hoeller S, Bourgau C, et al: Recurrent numerical aberrations of JAK2 and deregulation of the JAK2-STAT cascade in lymphomas. Mod Pathol 2009;22:476-487.

28 Muenst S, Läubli H, Soysal SD, et al: The immune system and cancer-evasion strategies: therapeutic concepts? J Intern Med 2016, Epub ahead of print.

29 Fankhauser CD, Curioni-Fontecedro A, Allmann V, et al: Frequent PD-L1 expression in testicular germ cell tumors. Br J Cancer 2015; 113:411-413.

30 Rizvi NA, Mazières J, Planchard D, et al: Activity and safety of nivolumab, an anti-PD-1 immune checkpoint inhibitor, for patients with advanced, refractory squamous nonsmall-cell lung cancer (CheckMate 063): a phase 2, single-arm trial. Lancet Oncol 2015; $16: 257-265$.
31 Velcheti V, Schalper KA, Carvajal DE, et al: Programmed death ligand-1 expression in non-small cell lung cancer. Lab Invest 2014; 94:107-116.

32 Sterlacci W, Stockinger R, Schmid T, et al: The elderly patient with surgically resected nonsmall cell lung cancer - a distinct situation? Exp Gerontol 2012;47:237-242.

33 Sterlacci W, Wolf D, Savic S, et al: High transforming growth factor $\beta$ expression represents an important prognostic parameter for surgically resected non-small cell lung cancer. Hum Pathol 2012;43:339-349.

34 Sterlacci W, Tzankov A, Veits L, et al: A comprehensive analysis of p16 expression, gene status, and promoter hypermethylation in surgically resected non-small cell lung carcinomas. J Thorac Oncol 2011;6:1649-1657.

35 Sterlacci W, Tzankov A, Veits L, et al: The prognostic impact of sex on surgically resected non-small cell lung cancer depends on clinicopathologic characteristics. Am J Clin Pathol 2011;135:611-618.

36 Sterlacci W, Fiegl M, Hilbe W et al: Deregulation of p27 and cyclin D1/D3 control over mitosis is associated with unfavorable prognosis in non-small cell lung cancer, as determined in 405 operated patients. J Thorac Oncol 2010;5:1325-1336.
37 Augustin F, Fiegl M, Schmid T, et al: Receptor for hyaluronic acid-mediated motility (RHAMM, CD168) expression is prognostically important in both nodal negative and nodal positive large cell lung cancer. J Clin Pathol 2015;68:368-373.

38 Gadiot J, Hooijkaas AI, Kaiser AD, et al: Overall survival and PD-L1 expression in metastasized malignant melanoma. Cancer 2011;117: 2192-2201.

39 Gevensleben H, Dietrich D, Golletz C, et al: The immune checkpoint regulator PD-L1 is highly expressed in aggressive primary prostate cancer. Clin Cancer Res 2015, Epub ahead of print.

40 Soria JC, Cruz C, Bahleda R, et al: Clinical activity, safety and biomarkers of PD-L1 blockade in non-small cell lung cancer (NSCLC). 2013 European Cancer Congress, abstract 3408.

41 Wagner PL, Hyjek E, Vazquez MF, et al: CXCL12 and CXCR4 in adenocarcinoma of the lung: association with metastasis and survival. J Thorac Cardiovasc Surg 2009; 137: 615-621.

42 Otsuka S, Klimowicz AC, Kopciuk K, et al: CXCR4 overexpression is associated with poor outcome in females diagnosed with stage IV non-small cell lung cancer. J Thorac Oncol 2011;6:1169-1178. 